\title{
NUM ESPELHO DE MULHER: CEGUEIRA NORMAIIVA E QUESTÕES DE DIREITOS HUMANOS NÃO RESOLVIDAS*
}

\author{
Laura Nader \\ University of California, Berkeley - Estados Unidos
}

Resumo: Este artigo examina as restrições que regem as declarações de direitos humanos, reconhecendo os principais avanços conceituais ao mesmo tempo em que dirige a atenção para questões não resolvidas, que são culturais na sua maioria. A cegueira normativa refere-se a questões de realce relativas a mutilações sexuais $e$ de outra natureza, testes de armas, ou controle de armas como é visto das margens. Um reconhecimento dos abusos de direitos humanos resultantes do comercialismo global é crucial para um movimento de direitos humanos não-hegemônico enquanto a comparação exige que nos tornemos mais autoconscientes do papel do ativismo de direitos humanos euro-americano como projeto hegemônico. Um salto à frente requer uma filosofia de direitos humanos de calibre maior na qual nenhum lugar ou país ou empresa esteja isento.

Palavras-chave: direitos humanos, excisão, islã, mulher.

Abstract: This paper reviews the constraints governing declarations of human rights, recognizing the major conceptual progress while also directing attention to unresolved issues that are mainly cultural. Normative blindness refers to salient issues regarding sexual and other mutilations, weapons testing, or arms control as viewed from the margins. A recognition of human rights abuses resulting from global commercialism is critical to a non-hegemonic human rights movement while comparison requires us to become more self-conscious about the role of Euro-American human rights activism as a hegemonic project. A leap forward calls for a broad gauged philosophy of human rights in which no place or country or enterprise is exempt.

Keywords: excision, human rights, islam, women.

* Este artigo foi apresentado no dia 7 de março de 1998 na Rothko Chapel, em Houston, Texas. A autora agradece a ajuda crítica de muitos colegas, especialmente Dr. Alison Renteln, profundo conhecedor das literaturas dos direitos humanos. Rania Milleron pelo investimento nas questões de saúde e direitos humanos, e Suzanne Calpestri pela criteriosa atenção ao material de direitos humanos de relevante interesse para a antropologia. 
É apropriado celebrar o $50^{\circ}$ aniversário da Declaração de Direitos Humanos das Nações Unidas de 1948 porque aquela declaração foi um marco na história da comunidade humana. Também é importante reconhecer a atenção das Nações Unidas para com os direitos humanos da mulher desde 1948. Revendo a situação dos direitos humanos e dos direitos humanos da mulher em particular, no entanto, nós nos damos conta que este é mais um momento de reflexão do que de celebração. Como vemos através da mídia, dos contatos pessoais e nossa própria análise do que acontece no mundo, precisamos de ativistas de direitos humanos hoje mais do que nunca - ativistas que sejam parte duma cidadania mundial alertada para a velocidade do impacto tecnológico e a centralização do poder com seus aspectos impessoais.

Minhas observações vão abranger diversos tópicos. Primeiro, eu vou rever as restrições que governam a declaração original para trazer à tona o progresso conceituai principal feito desde 1940. Segundo, vou comentar os temas não resolvidos da declaração, temas que, quando levados adiante, abriram quadros mais abrangentes para o trabalho de direitos humanos, incluindo perspectivas das margens $-\mathrm{o}$ terceiro e quarto mundo, o mundo das mulheres. E, finalmente, vou chamar atenção para um reconhecimento dos abusos dos direitos humanos causados por um comercialismo selvagem, fora de controle. Durante meu discurso eu usarei uma visão comparativa que requer que nos olhemos no espelho desde o início, para estarmos conscientes do papel de ativistas americanos de direitos humanos. Foi observado que os ativistas de direitos humanos precisam dar um salto adiante nesta virada de século. Para isto acontecer é preciso que a definição de violações específicas dos direitos humanos seja calcada numa filosofia abrangente sobre o sofrimento humano uma filosofia que ultrapasse posições sectárias.

\section{Primeiras restricões}

A Declaração das Nações Unidas teve grande importância pela ousadia da tentativa. Imaginem o cenário após a Segunda Guerra Mundial. Representantes de nações ocidentais, comunistas e de Terceiro Mundo estavam discutindo em termos filosóficos o conteúdo da futura declaração de direitos humanos, cada qual do seu próprio ponto de vista - os chineses insistindo para que a filosofia confucionista fosse incorporada à declaração, os católicos querendo os 
ensinamentos de São Tomás de Aquino, os liberais advogando as posições de John Locke e Thomas Jefferson, e os Comunistas as de Karl Marx. Foi uma tarefa medonha, levar partidos tão diversos a concordarem sobre o que eram direitos humanos. Mas eles deram o primeiro passo, pelo menos.

Como a maioria dos ativistas de direitos humanos sabem, Eleanor Roosevelt foi presidente da Comissão de Direitos Humanos da ONU. Roosevelt foi sempre persistente em lembrar a seus colaboradores de que eles eram responsáveis por escrever uma declaração aceitável a todas as religiões, ideologias e culturas. Entretanto, como é sabido, mesmo com todos os seus esforços, houve enormes desacordos e vazios. Não havia representantes das populações indígenas do mundo, dos povos islâmicos do chamado "Terceiro Mundo", e a representação das mulheres era pouco expressiva, apesar da presença da Sra. Roosevelt. Mulher prática, Eleanor Roosevelt lidava com o que tinha diante de si - países do Leste querendo limitar a carta a direitos sociais e econômicos de um lado, e de outro as declarações de liberdade ocidentais listadas na American Bill of Rights e na Declaração de Direitos do Homem francesa de 1789. No fim, o grupo chegou a um texto aceitável, incluindo artigos inspirados no socialismo que garantiam emprego integral, moradia adequada, saúde pública decente e uma previdência social vitalícia.

Deve ser reconhecido que a Sra. Roosevelt não sacrificou princípios básicos para alcançar a unanimidade. Em suas próprias palavras: "Esperamos que sua proclamação pela Assembléia Geral seja um evento semelhante à Declaração dos Direitos do Homem pelos franceses em 1789, à adoção da Bill of Rights pelo povo dos Estados Unidos, e à adoção de declarações comparáveis em diferentes épocas em outros países." (Bergen 1981, cap. 6, p. 73). Os primeiros anos das Nações Unidas foram agitados. Anos depois, na nominação da Sra. Roosevelt para o prêmio Nobel, que ela não ganhou, Jean Monnet, pai do Mercado Comum elogiou-a (Lash, 1972, p. 337): "Fundamentalmente, eu penso que sua grande contribuição foi sua persistência em colocar em prática sua profunda crença na liberdade e na igualdade... para ela, o mundo era realmente um só, todos os seus habitantes." Como a própria Sra. Roosevelt colocou:

Onde, afinal de contas, começam os direitos humanos universais? Em pequenos lugares, perto de casa - tão perto e tão pequenos que não podem ser vistos em nenhum mapa do mundo. Entretanto, eles são o mundo de cada pessoa 
individualmente; a vizinhança onde ela vive; a escola ou faculdade que frequenta; a fábrica, fazendas ou fabricas onde ela trabalha. São estes os lugares em que todo homem, mulher ou criança deseja justiça igual, oportunidades iguais, dignidade igual, sem discriminação. A não ser que esses direitos tenham significado lá, eles pouco significam em qualquer lugar. (Romany, 1994).

Eleonor Roosevelt e as mulheres do New Deal pertenceram à sua época. Foram antes de tudo reformadoras, e sempre consideraram seus posicionamentos como possíveis modelos a serem emulados por outras mulheres educadas, mas acima de tudo isso elas eram assistentes sociais: elas sabiam o que era melhor para os outros (Hoff-Wilson; Lightman, 1984; Berger, 1981). Como outros observaram, os sucessos que obtiveram em defesa das mulheres foram transitórios: os magros ganhos das mulheres na política brotaram de sua posição estrutural, enraizada em ideologia cultural e instituições sociais, e a análise desses fatores e uma agenda para a mudança dos mesmos estavam fora do alcance de quem reduzia o seu enfoque aos direitos e aspirações individuais e à participação política, em vez das causas primárias.

\section{Questões não resolvidas}

As complexas questões não resolvidas do período da Sra. Roosevelt são ainda atuais quando os debates são formulados em termos dicotômicos: deveríamos nos concentrar em direitos individuais em detrimento dos direitos coletivos? Deveríamos tratar de direitos coletivos em detrimento dos direitos individuais? Além disso, o equilíbrio entre a soberania nacional e os direitos humanos internacionais apresentam mais problemas, e finalmente a questão dos direitos humanos como parte de um movimento hegemônico ocidental e predominantemente americano é uma questão cada vez mais debatida (Renteln, 1990). Na verdade, a comissão dos Direitos Humanos e a ONU como um todo eram compostas predominantemente de ocidentais. E realmente o movimento para a criação de um novo aparato internacional para a promoção de direitos humanos era comandado em grande parte por americanos. O Departamento de Estado norte-americano orquestrou os primeiros esboços, os encontros cruciais aconteceram nos EUA, e até mesmo o próprio objetivo - esboçar uma carta de direitos, uma International Bill of Rights — tinha um 
sabor norte-americano inegável. Todos têm direito à vida, liberdade, segurança pessoal, liberdade de pensamento, consciência e religião, liberdade de movimento... ninguém pode ser escravizado, torturado, preso, detido ou exilado arbitrariamente. E todos menos dois rascunhos foram escritos em inglês. $\dot{\mathrm{E}}$ imprescindível que entendamos algo sobre a confecção desse documento para colocar em perspectiva os desafios com que ainda nos deparamos. Deixem-me abordar essas questões uma de cada vez.

A atenção centrada nos direitos individuais versus direitos coletivos foi crucial para as populações indígenas. Nesse ponto, a Declaração da ONU não foi muito útil para o povo indígena. Muitos nativos americanos acreditam que os direitos coletivos dos índios são os mais importantes e os mais ameaçados de todos os direitos dos índios americanos. O direito ao autogoverno, o direito de manter propriedade comunitária de terras e recursos, o direito de preservar suas culturas e línguas, e sua religião - todos eles argumentam a favor de um direito humano de grupo protegido. Grupos indígenas precisam de suas próprias terras e sua própria água para sobreviver, e o confisco ou a negação disso equivale, com efeito, a uma política de etnocídio (Nader; Ou, 1998).

Richard Falk (1992), um estudioso que se distinguiu por sua lucidez em assuntos de direitos humanos, argumentou que a desconsideração para com as populações indígenas pode ser descrita como uma área de "cegueira normativa" - uma cegueira que acompanha uma visão de modernização que vê culturas pré-modemas como uma forma de atraso a ser superado para o bem das populações indígenas. Nesta perspectiva, raciocina-se não por respeito à autonomia cultural de povos indígenas, mas antes visando a sua assimilação organizada e equitativa no espaço benevolente do ethos modernizante. Em nome do desenvolvimento, populações indígenas foram e ainda estão sendo destruídas e deslocadas em várias partes do terceiro mundo (Falk, 1992, p. 4748). Suas riquezas em biodiversidade e propriedade intelectual estão sendo roubadas. A própria exclusão do processo de formulação dos direitos já é uma negação de direitos humanos de acordo com Falk, e é fácil ver por quê. As questões indígenas não fizeram parte do esforço de 1948.

Similarmente, a preocupação com o Estado em detrimento de assuntos privados lidando com interações íntimas excluiu muitos dos direitos humanos ligados especificamente à mulher: tortura, espancamento de esposas, direitos 
reprodutivos, assédio sexual, a própria vida. Desde 1948, a compreensão da dicotomia público/privado estimulou volumosa pesquisa jurídica sobre aspectos não-estatais dos direitos humanos e seus efeitos para as vidas de milhões de mulheres em suas casas e locais de trabalho.

A ênfase em direitos humanos internacionais versus direitos humanos universais invadiu as delicadas questões de relativismo e soberania nacional. Aliás, é neste campo que vimos as mais estridentes performances de militantes dos direitos humanos, freqüentemente com idéias reformistas em mente. Sem qualquer forma de autoquestionamento, e munidos de uma dose monumental de certeza moral, esses grupos militantes apresentavam-se em conferências internacionais de direitos da mulher, muitas vezes em companhia de nacionalistas com mentalidade igualmente reformista. Voltaremos a este assunto mais tarde.

E, finalmente, temos os problemas de "superioridade ocidental" sobre os quais Edward Said (1979) escreveu, o discurso dos direitos humanos como parte de um discurso ocidental ou até mesmo de um discurso ocidental hegemônico. Qualquer pessoa sensibilizada para as questões interculturais, ou qualquer cidadão minimamente informado de algum país do chamado terceiro mundo, sabe que esse discurso é capaz de provocar cinismo sobre toda a noção de direitos humanos. Freqüentemente tal discurso aparece em nossos jornais e só é percebido como uma idéia universal, ou que deva ser universal, de direitos humanos. Por exemplo, recentemente no New York Times (09/02/1998) apareceu uma manchete - COMO OS CLÉRICOS DOS EUA VÊEM A RELIGIÃO NA CHINA, com o subtítulo - Uma questão-chave de direitos humanos: liberdade de religião na China. O artigo começa: "Uma delegação de altos personagens religiosos americanos começou a chegar hoje a Pequim para uma visita de três semanas à China para examinar as condições de liberdade religiosa neste país, uma das questões mais voláteis de direitos humanos na diplomacia americana." E depois, "Em sua busca de diálogo, o grupo vai confrontar uma nítida diferença de perspectivas sobre o significado de liberdade religiosa."

Contemplem a assimetria por um momento. Imaginem uma delegação chinesa nos EUA para examinar o direito dos nativos americanos de praticarem liberdade religiosa, quer fosse ela a dança dos fantasmas, o culto do peyote, ou buscas visionárias. Apesar da Declaração de Liberdade do índio Americano de 1978, nos anos 80 e 90 as cortes federais negaram a liberdade 
religiosa dos nativos norte-americanos em dez casos consecutivos (veja, por exemplo, Lyng vs. Northwest Indian Cemetary Protective Association, em Nader e Ou, 1998).

$\mathrm{Ou}$, imaginem uma delegação chinesa que venha examinar perseguições políticas de minorias norte-americanas. Os EUA têm um dos maiores índices (se não o maior) de encarceramento do mundo, em prisões povoadas principalmente por minorias americanas.

Desde o início, direitos humanos têm sido aquilo que os americanos levam para os outros. A Faculdade de Direito de Boalt Hall da Universidade da Califórnia, em Berkeley, abriu recentemente uma clínica de direitos humanos que prestará serviços jurídicos gratuitos e investigará abusos de direitos humanos para clientes nacionais e internacionais. A história de sua abertura indica que dois dos primeiros clientes da clínica são de países africanos, refugiados individuais em busca de asilo político junto ao Serviço de Imigração e Naturalização dos EUA - o que não é essencialmente um mau serviço a oferecer, mas quando visto como parte do todo, contribui para uma imagem distorcida da situação.

Ao preparar este artigo, gastei semanas lendo a literatura de direitos humanos, cuja quantidade é prodigiosa e, em grande parte, técnica e abstrata. Mas, um desenvolvimento muito útil encontrado nos escritos recentes foi a presença de advogados de direitos humanos de outros países, que têm muito a nos ensinar sobre nós mesmos. Por exemplo, um interessante artigo sobre Programas de Ajustamento Estrutural (Kuenyehia, 1994, p. 430) aponta para as consequências negativas do ajustamento estrutural para a condição humana. $\mathrm{O}$ autor indica que houve em Gana um retrocesso ao invés de progresso nas áreas de nutrição, educação, emprego e bem-estar social. Ativistas do terceiro mundo argumentam que direitos a comida, educação, emprego e assistência social perderam o sentido por causa das condições geralmente impostas pelo Fundo Monetário Internacional e que têm de ser cumpridas por um país beneficiário antes de receber financiamento do Banco Mundial, ou antes do país ser considerado merecedor de crédito internacional. Como resultado de Programas de Ajustamento Estrutural em Gana e outros lugares a carga de trabalho imposta às mulheres tem crescido a níveis desumanos. Outros (Morsey, 1993) documentaram experiências com tecnologias reprodutivas de origem norte-americana, como da Norplant, como violações escancaradas de direitos humanos. As instituições estão anulando umas às outras. O ponto específico 
aqui é que os ativistas norte-americanos de direitos humanos estão sendo neutralizados pelo seu próprio governo.

Tais problemas não eram ressaltados $\mathrm{cm} 1948$ principalmente porque os participantes eram limitados, os alvos naquele momento eram as nações-estado, e os processos de globalização eram relativamente limitados. Hoje, tecnologias de transporte, viagem $€$ turismo, atenção da mídia, educação transcultural, e o aumento logarítmico da interação humana de todas as variedades criaram tanto oportunidades quanto obstáculos aos direitos humanos. No lado vantajoso os turistas, por exemplo, desempenharam um importante papel regulatório na revolta de Chiapas no sul do México, e turistas de vários países também tiveram um papel importante na defesa dos aldeãos de Tepoztecan contra a violência estatal em Morelos, México. O caso de Tepoztlan foi encorajador porque, além dos turistas, havia entre outros ativistas pessoas locais, americanos manifestando-se contra empresas de seu país, jornalistas americanos, canadenses, europeus e também mexicanos, e a tecnologia de vídeo permitiu gravar violações de direitos humanos no local da ocorrência.

As perspectivas de avanço dos direitos humanos estão ligadas às possibilidades de reconstrução cultural que dependem de um processo aberto de comunicação, livre de interferência dogmática. Nós precisamos de uma filosofia de direitos humanos mais aberta para qualquer salto adiante. Já que a concepção de direitos humanos transcende a cidadania do indivíduo, o apoio aos direitos humanos pode vir de qualquer um - sendo ele ou não cidadão do mesmo país do indivíduo cujos direitos foram ameaçados - mais motivo ainda para aplicar a razão prática. Tanto a humildade quanto a paixão são componentes importantes de qualquer plano de ação, e como podemos ver, a primeira, segunda e terceira geração de direitos humanos indicam que estamos fazendo avanços conceituais.

Uma professora de direito canadense (Hernandez-Truyol, 1996) coloca a possibilidade de reconstrução cultural da seguinte maneira:

É imperativo que qualquer análise de práticas culturais, para ser válida, deve ser conduzida da perspectiva tanto dos "de dentro" quanto dos "de fora". Por exemplo, as feministas do estado industrial precisam pensar seriamente sobre como certas práticas podem ser explicadas aos outros. Considerem, por exemplo, a feminização da pobreza, a negação de benefícios previdenciários a mães que têm mais filhos do que o Estado pensa que deveriam ter, enquanto pais não são parte da equação de reforma do bem-estar. 
Ela continua ressaltando o fato de que: "em nenhuma sociedade hoje as mulheres têm as mesmas oportunidades que os homens... e a constatação de que a desigualdade dos sexos é uma realidade global... impede que os americanos considerem problemas e preocupações de gênero como existentes apenas em "outros lugares", como em países de Terceiro Mundo ou de tradições não-ocidentais. $\mathrm{O}$ ponto é que vivemos todos em casas de vidro. Falamos do uso de armas biológicas por Sadam Hussein. Um número recente da revista Nation (9 de março, 1998, p. 9) documenta o uso de armas biológicas e químicas pelos Estados Unidos contra Cuba.

\section{Um esforço de direitos humanos}

Eu gostaria agora de mudar o foco de temas não resolvidos para o Oriente Médio, onde a violação de direitos humanos tanto por pessoas locais quanto estrangeiras tem sido desenfreada. Qualquer um com um senso de justiça bem regulado teria sido afetado pela última incursão de Israel no Líbano, ou pela Guerra do Golfo de 1991 e o bombardeio de Bagdad, que incluíram bombardeios aleatórios a civis. Particularmente, olhar a Guerra do Golfo na TV foi uma experiência surrealista que deixou uma marca em muitos de nós. Naquele momento eu pensei que se houvesse mais simetria, mais respeito mútuo, tal bombardeio talvez não tivesse ocorrido. Foi o começo de um esforço pelos direitos humanos. Uma amiga e eu juntamos esforços aos de mais duas colegas para organizar o International Council for Women in the Arts (Conselho Internacional para Mulheres nas Artes). O primeiro desafio do ICWA foi financiar mulheres artistas árabes, planejar uma exibição e fazer a estréia na cidade de Washington, onde seria visível aos políticos americanos. Não foi tarefa fácil. Nosso objetivo era humanizar a situação demoníaca e desumanizada do Oriente Médio, abrir canais para a comunicação.

O ICWA foi uma organização que surgiu das cinzas da Guerra do Golfo. A exposição atraiu mais pessoas para o Museu Nacional de Mulheres nas Artes em Washington do que qualquer outra exibição até o momento. Eu escrevi sobre isso noutros lugares, aqui desejo apenas mencionar algumas dessas mulheres artistas árabes que, em suas próprias palavras e obras de arte, ilustram seus sentimentos em relação aos direitos humanos - conflito armado, ocupação, um ambiente destruído (Nashashibi; Nader; Adnan, 1994). Suas histórias eram pontuadas por suas reações à guerra, poluição, emigração, ciclo 
de vida familiar, e outros eventos. O trabalho delas revelou uma arte política de resistência ativa à dominação criando uma nova cultura. O leste árabe foi um campo de batalha nos séculos 19 e 20. Durante os últimos dois séculos os árabes foram subjugados pelo domínio estrangeiro, uma situação que não foi ignorada por essas artistas. Violência e tragédia, destruição e morte são catalisadores comuns. Alguns exemplos:

Saloua Raouda Choucair - uma das primeiras artistas abstratas no Líbano e uma das melhores escultoras no mundo árabe - lembra que seu compromisso com a arte começou como um desafio ao seu professor de filosofia na Universidade Americana de Beirute, Charles Malik (um dos autores eurocêntricos da Declaração Universal dos Direitos Humanos) que afirmou que “...a arte arábica é uma arte decorativa de grau inferior, longe de ser arte pura, porque os árabes não foram inspirados pelo nu". Choucair, estudante de matemática e física, começou a explorar a geometria, a forma e a cor da arte islâmica.

Injii Efflatoun, uma artista egípcia, participou da agitação que envolveu a região após a Segunda Guerra Mundial e que tornou as mulheres artistas mais abertamente políticas. Sua proposta era marxista - reestruturar a relação entre os donos da terra e os camponeses. Ela passou quatro anos presa por causa de suas crenças políticas, uma experiência que propiciou base para muitas de suas pinturas.

O conflito da Palestina, que resultou em cinco guerras entre Israel e países árabes desde 1948, adicionou uma outra dimensão à luta pelos direitos humanos. Monta Hatoum, uma artista palestina de um campo de refugiados no Líbano, foi atraída para as artes dramáticas. Sua arte envolve o uso político de opostos binários, contrastando ordem e caos, opressão e resistência, sempre revelando dois lados de uma mesma realidade: vencedor/vítima, força/ fraqueza, fardado/nu.

O diálogo de ocupação é representado por Houria Niati da Argélia. Niati lembra ter sido presa por autoridades francesas por ter escrito slogans anticolonialistas nos muros quando tinha doze anos. Anos depois Niati iniciou sua série "Não à tortura", dizendo que mulheres na Algéria estavam lutando e morrendo. Elas eram torturadas. Noções ocidentais do oriental imaginavam um mundo fantasioso de mulheres. As mulheres árabes de Delacroix eram seminuas. As mulheres argelianas de Niati não repetem o esplendor de Delacroix. Antes, elas desmascaram a dinâmica de poder inerente nas imagens de Delacroix. Niati diz não à tortura em todos os lugares. 
O diálogo de colonialismo e ocupação na Palestina inspirou Lila Al Shawa de Gaza a registrar as duras realidades da ocupação de Israel. Ela fotografou grafites nos muros de Gaza antes de serem encobertos pelo exército de ocupação israelense. Ela fotografou o mapa da Palestina que havia sido desenhado nos lados das barricadas de cimento que cercam as ruas de Gaza para prevenir contra a fuga de crianças atiradoras de pedras. Falando de seu trabalho e comentando sobre os silêncios dos "civilizados", Al-Shawa diz: "Eu registrei um método de comunicação e punições que foram santificados pelo "mundo civilizado."

Talvez a citação mais comovente venha de Leila Kawash, uma artista iraquiana, que fala sobre como sua arte foi afetada pela Guerra do Golfo.

Durante a guerra com o Iraque... quando os americanos atingiram esse refúgio cheio de crianças, e todas saíram correndo, uma delas gritou "Allah el Akbar" (Deus é Grande). Eu estava pintando esse quadro e quando pensei de novo nestas palavras... era como se esse menino tivesse acumulado toda a força... como se estivesse combatendo a guerra toda com duas palavras. Eu pintei essas palavras com spray e elas apagaram todo o dourado que eu estava pondo antes.

Kawash perdeu a irmã, também uma artista, como resultado dos bombardeios esporádicos da primeira administração de Clinton.

Sentimentos de traição foram articulados pelas mulheres artistas e resumidos pela artista de Gaza que fala dos terríveis sentimentos que os árabes têm em relação ao Ocidente, "um poder que está tentando destruir você sem nunca tentar entender o que você é... que você é uma cultura muito antiga que você é um povo que vem de uma grande civilização, que suas raízes vêm de milhares de anos". Como um comentarista disse sobre o trabalho de artistas árabes, "seu trabalho parece menos uma busca por identidade do que uma expressão de dor". Falam do tipo de dor que os ativistas de direitos humanos talvez possam entender. No entanto, as preocupações das mulheres artistas árabes com os direitos humanos não são as mesmas dos ativistas de direitos humanos mais loquazes, que em geral evitam discussões sobre a violação de direitos humanos por forças externas para concentrarem-se em assuntos tais como a circuncisão feminina, excluindo preocupações com os milhares de mulheres e crianças que morreram no bombardeio de Bagdá ou com as crianças atiradoras de pedras cujos direitos humanos são regulados na Palestina/ Israel. Como as artistas nos lembram, houve silêncios ensurdecedores da parte do mundo "civilizado". 
Muitos de nós somos parte do silêncio hegemônico no que diz respeito aos temas politicamente incorretos dos direitos humanos. Lembremos que, em muitos países, a objeção à noção de direitos humanos se remete a sua origem ocidental. E com boa razão. Privilegiar preocupações ocidentais de direitos humanos é etnocêntrico, e a atenção atribuída a esses temas não deve ofuscar uma definição mais abrangente dessas preocupações. A prioridade dada em geral às preocupações ocidentais tem a ver com sua superioridade posicionai. Eles têm circuncisão de mulheres, o que é barbárico. Nós não, talvez.

\section{Saúde e direitos humanos}

Um recente relatório sobre saúde pública e a Guerra do Golfo Pérsico (Hoskins, 1997) relata as consequências de bombardeios aleatórios de civis. Mais de 5 anos depois do fim da Guerra do Golfo Pérsico, civis iraquianos sobrevivem num estado de dificuldades extremas, no qual saúde, nutrição, educação, água, saneamento, e outros serviços são mínimos. Acredita-se que 500 mil crianças morreram desde a guerra principalmente por desnutrição, diarréia e doenças que poderiam ter sido prevenidas por vacinas. Serviços de saúde mal funcionam devido à escassez de suprimentos e equipamentos.

O Iraque antes da Guerra do Golfo era um país de renda média alta com uma infraestrutura social moderna. O colapso da saúde, da água e do saneamento, e outros serviços sociais essenciais que se seguiram à Guerra do Golfo levaram a um crescimento dramático de doenças infecciosas como cólera e tifo e doenças relacionadas à desnutrição. $\mathrm{O}$ impacto sobre a mortalidade materna e perinatal foi considerável. Mulheres iraquianas tiveram que assumir responsabilidades redobradas como resultado da Guerra do Golfo Pérsico. Na verdade, mais de $10 \%$ das mulheres casadas do Iraque são viúvas.

Grupos internacionais de pesquisa documentaram depressão generalizada, ansiedade, dor de cabeça e insônia, perda de peso, irregularidade menstrual, dificuldades de amamentação e outras doenças. Populações humanas também foram sujeitas a riscos quando sua fonte de água foi diretamente afetada, e os problemas ambientais que resultaram em contaminação tóxica de várias espécies causou grandes estragos posteriores.

$\mathrm{Na}$ verdade as pessoas que têm procurado a saída desse marasmo são ativas no atual movimento de saúde e direitos humanos (Heggenhaugen, 1997). Profissionais de saúde pensam que o quadro de referência dos direitos 
humanos é mais útil a desafios da saúde pública moderna do que qualquer quadro na tradição biomédica. Profissionais de saúde pública se dão conta cada vez mais de que eles têm que lidar diretamente com os conceitos socio-econômicos que determinam quem vive e quem morre, quando e de quê. Por causa da importância atribuída a questões sociais na Escola de Harvard de Saúde Pública, os formandos recebem junto com seu diploma uma cópia da Declaração Universal dos Direitos Humanos, com atenção especial ao artigo 25 sobre direitos humanos e saúde. Trabalhadores da saúde pública não precisam decidir o que é pior - a invasão do Taliban no Afeganistão (Faiz, 1997), ou a iniciativa da Guerra do Golfo, ou as políticas da Indonésia no Timor Leste. Todos estes acontecimentos são ruins para a saúde das pessoas. Além disso, nós podemos todos concordar com Jonathan Mann (1996) e outros (Rodriguez-Trias, 1992). "Uma sociedade dominada por homens é uma ameaça à saúde pública." Agressões de maridos, ex-maridos e amantes causam mais danos a mulheres que acidentes de trânsito, estupros e assaltos violentos todos juntos. O modelo global para pensar holisticamente sobre a saúde e o movimento de direitos humanos pode ser ilustrado se retornarmos ao tema da circuncisão e/ ou cliterodectemia.

No passar dos anos eu desenvolvi uma antipatia com relação a conferências públicas e discussões sobre cliterodectemia ou circuncisão feminina na África. Freqüentemente, muito freqüentemente, os confrontos em tom acusatório e arrogante resultam em posturas rígidas de ambos os lados. Essas discussões sempre me lembram o sati na Índia, que quando condenado e banido pelos britânicos apenas aumentou. Eu sempre achei que havia algo de errado com o diálogo sobre mutilação sexual, que era muito etnocêntrico, muito carente de introspecção.

Algumas semanas atrás meu bibliotecário me passou um livro recentemente publicado intitulado Mutilações Sexuais - Uma Tragédia Humana (Denniston; Milos, 1997). Mutilação Sexual faz o que deveria ter sido feito anos atrás. O trabalho foi o resultado do $4^{\circ}$ Simpósio Internacional Sobre Mutilações Sexuais em Lausanne, Suíça (o primeiro aconteceu em 1989 na Califórnia). Permitam-me transcrever uma parte do prefácio para que possam perceber o tom da abordagem:

Mutilação sexual é um problema global que afeta 15,3 milhões de crianças e jovens adultos anualmente. Em termos de sexo, 13,3 milhões de meninos e 
2 milhões de meninas são involuntariamente sujeitos a mutilação sexual todo ano. A violação ocorre com o primeiro corte no corpo de outra pessoa. [...] Termos como "circuncisão" e "corte genital" podem ser menos ameaçadores a nossas sensibilidades, mas, em última análise, eles complicam a questão ao mascarar o que, na verdade, está sendo feito com bebês e crianças [...] De acordo com o sistema de crenças dessas culturas que praticam a mutilação sexual de crianças, os órgãos sexuais não pertencem à pessoa a quem eles estão grudados: ao invés, eles são vistos como propriedade comum, sob o controle direto dos médicos, feiticeiros, figuras religiosas, velhos da tribo, parentes ou seus agentes [...] O número de crianças que morrem em conseqüência direta da mutilação sexual tradicional é grande, $\mathrm{O}$ número de crianças que quase morrem é maior. Calcula-se que, nos Estados Unidos, 229 bebês morrem cada ano como resultado de complicações da amputação do prepúcio. Além disso, 1 em cada 500 sofre sérias complicações necessitando atenção médica urgente [...] Mutilações sexuais tradicionais ocorrem principalmente na Saarásia (África e Arábia Saudita) e na Melanésia no Pacífico.

O prefácio continua: “A gênese quase espontânea da mutilação sexual por médicos em tempos históricos nos EUA fornece pistas interessantes sobre as origens da mutilação sexual na pré-história."

Eu também começo a notar que reportagens recentes de jornais sobre mutilação sexual são menos sensacionalistas. Talvez algo esteja mudando. $\mathrm{O}$ New York Times (19/12/1997) relatou uma decisão da corte suprema do Egito declarando que práticas tais como circuncisão não são práticas religiosas Islâmicas. Alguns dias depois, um artigo sobre pesquisas canadenses advogaria alívio à dor da circuncisão masculina (NYT, 30/12/1997). Essas notícias foram seguidas por um grande número de cartas ao editor, expressando satisfação com o fato de a comunidade médica finalmente reconhecer que os recém-nascidos sentem dor e perguntando: "Então por que muitos hospitais perpetuam uma prática para a qual não há nenhuma premente razão médica?" Outra dizia: "Vocês sabiamente rejeitam a mutilação genital na África, mas como podem não mencionar os quase 1.6 milhões de crianças que se tornam vítimas de circuncisão rotineira todo ano nos EUA?" (NYT, 03/01/1998).

O livro Mutilações Sexuais cobriu o mundo e incluiu os EUA em seu estudo. Não eram somente os direitos humanos dos outros, eram também os direitos humanos dos americanos. Eu aprendi muita coisa que não sabia ou não tinha notado antes de ler o livro. Por exemplo, entrevistas com pessoas tanto da África quanto dos EUA que aceitam mutilações sexuais afirmam que suas respectivas práticas de mutilação sexual são mínimas, sem dor, 
embelezadoras, indicadas por médicos, higiênicas, preventivas de doenças, sexualmente vantajosas, universais, medicamentadas e inofensivas. Tanto mulheres africanas quanto homens americanos são relutantes em acreditar que eles perderam qualquer coisa, não obstante a quantidade de tecido perdida.

Para ativistas de direitos humanos a circuncisão representa uma violação do direito fundamental do indivíduo à autonomia, segurança pessoal, integridade física, saúde física e mental e autodeterminação. A mutilação sexual de mulheres é praticada em 22 países. Muitos desses países são árabes ou muçulmanos; mutilação sexual de homens é praticada por 1 bilhão de muçulmanos, 300 milhões de cristãos, e 16 milhões de judeus.

Mas o capítulo sobre a institucionalização da mutilação sexual involuntária nos EUA foi o mais esclarecedor. Já em 1845 a insanidade era curada pela extração dos órgãos externos da mulher; havia práticas semelhantes para os homens. Isto se tornou um tratamento preferencial para a masturbação, epilepsia, prevenção de sífilis, hérnia, má digestão, inflamação da bexiga, artrite da bacia, curvatura da espinha e mais (veja por exemplo, Feibleman, 1997 e Sheehan, 1997). A mutilação sexual era usada para curar paralisia em meninas. Ela se tornou higiene moral. De 1914 em diante houve uma cruzada pela circuncisão involuntária em massa que se tornou um negócio. As justificativas foram se aperfeiçoando - cura para a frigidez, para infecção do aparelho urinário, prevenção da AIDS, câncer cervical das mulheres, câncer peruano - e os prepúcios descartados são vendidos para laboratórios de pesquisas biológicas e corporações multinacionais. $\mathrm{O}$ objetivo desse tratado histórico é indicar que quando a causa da histeria era a masturbação, depois a epilepsia, depois as doenças sexualmente transmissíveis, depois o câncer, o HIV, a cirurgia sexual prosseguiu, em nome da ciência. Como está a situação hoje não podemos saber. Numa conversa informal com uma administradora da Universidade da Califórnia em Berkeley, eu soube que ela tinha tido uma cirurgia sexual aos 17 anos, porque seu médico recomendou, pois isso a tomaria mais sexualmente atraente para seu marido. O mesmo médico mandou-a atar os seios em vez de amamentar seus bebês pela mesma razão. (Veja também Scheper-Hughes, 1991.)

No momento, médicos e enfermeiras estão se opondo à circuncisão, denunciando-a como uma epidemia iatrogênica, uma epidemia causada por médicos, sustentada pela invenção e proliferação de razões médicas infundadas, e a cada desqualificação científica dos antigos motivos médicos novas razões para a circuncisão são rapidamente inventadas. 
Questões de gênero não podem ser consideradas isoladamente, e não devem ser essencializadas. A abordagem tem que ser multidimensional para que possa ser humana. A Resolução Ashley Montagu para Terminar com a Mutilação Genital de Crianças no Mundo é uma petição à Corte Mundial de Haia. O exemplo da cirurgia sexual serve como modelo para diminuir a diferença entre eles e nós, entre o ideal e o real, um meio que torna desnecessário para os ativistas dos direitos humanos tanto o uso da cultura como escudo protetor de práticas que violam os direitos humanos das mulheres quanto $o$ uso dos direitos humanos como uma arma de imperialismo moral para oprimir outras comunidades e modos de vida. Durante a Guerra do Golfo Pérsico eu ouvi, na verdade, pessoas dizendo "bombardeiem eles, aquelas pessoas não sabem como tratar suas mulheres", ou "olhem o que eles fizeram aos Kurdos - bombardeiem eles!"

\section{Direitos humanos e comercialismo}

Eu gostaria de mencionar uma última questão a respeito dos direitos humanos e das mulheres. Os Direitos humanos foram concebidos em arenas nacionais e internacionais, em contextos formais e informais. O Estado foi enfatizado desde o início, e também, na segunda geração, os contextos privados domésticos e de trabalho. Em nenhum lugar aparece uma reflexão aprofundada do papel do crescente e penetrante sistema mercantil que promove a mutilação e justifica: "a escolha é dela". A escolha, como escrevi em algum lugar, é um conceito complicado que precisa ser desembrulhado, e muitas feministas trabalharam exatamente nisto na área de conceitos padronizados de beleza (Nader, 1997).

Bem mais de um milhão de mulheres nos EUA tiveram implantes de silicone nos seios - 80\% para aumentar o tamanho deles (Coco, 1994). Como poderíamos explicar a um grupo de ativistas de direitos humanos africanos, que vêem tal atividade como uma mutilação, por que esta cirurgia acontece? Como levaríamos pessoas de outras culturas a entender a conexão entre o tamanho dos seios de uma mulher e sua autoconfiança, seu bem-estar pessoal e valor social, quando para os africanos isso parece uma forma de lavagem cerebral, uma colonização patriarcal da mente e do corpo da fêmea, um fenômeno antinatural. 
Como nós todos sabemos, a indústria da beleza é bem organizada - uma grande quantidade de dinheiro está em jogo. As mensagens que se destacam em suas imagens de beleza comercial são de juventude, magreza, seios grandes, rosto estilo europeu, e passividade. Também é vendida a promessa de auto-aprimoramento por disseminação em massa das imagens oficiais de beleza. O que um escritor chamou de bombardeio por saturação das mentes das mulheres deixa pouco espaço para as realidades da existência física. Em suma, as imagens comerciais da mulher ideal representam a melhor propaganda de beleza que o dinheiro pode comprar, encorajando as mulheres a satisfazer os requerimentos através de cirurgias: face lifting, cirurgia de pálpebras, injeções de colágeno, plásticas do nariz, lipoaspiração, e várias formas de cirurgia nos seios. A consumidora insegura da indústria de beleza se torna uma paciente, uma inválida de beleza deformada. Sua doença social, feiúra, só pode ser curada com um bisturi. O papel chave do cirurgião plástico é diagnosticar seios pequenos como doentes (uma doença construída chamada hipertrofia), e prescrever tratamento ou cura - a criação e construção do "seio oficial." Não é incomum achar cirurgiões plásticos anunciando "escultura de corpos", mas o enfoque tem sido nos seios das mulheres.

Entender os implantes de silicone nos EUA exige a investigação do partriarcado, do marketing empresarial e da cirurgia plástica organizada. $\mathrm{O}$ seio feminino saudável conceitualizado em termos de "falta", resulta na criação do "seio oficial." Será que este exemplo constitui a violação dos direitos humanos da mulher? Pergunte à mulher que sofreu sérias complicações médicas, ou pergunte à mulher africana. Em ambas as práticas, de circuncisão e de aumento de seios, a mutilação ocorre teoricamente em seu benefício, para a re-criação de sua aparência feminina. A cirurgia nos seios femininos nos EUA possui um significado social muito semelhante ao da mutilação sexual na África. Em ambos os lugares a escolha da cirurgia reconstrutiva se dá fora do indivíduo, em nosso país como resultado de um processo de comercialização onde a mulher é mecanizada, medicada e mercantilizada.

Se para algumas pessoas a questão de implantes de seios está na área cinza em termos de abusos de direitos humanos, talvez a comercialização da vida possa ser considerada mais claramente do domínio dos direitos humanos (Burrows, 1996). Pergunte a John Moore, a fonte original das células "MO", registradas com a patente americana $\# 4,438,032$ : "Como é se sentir patenteado? Aprender de repente que eu era só um pedaço de material... está muito 
além de qualquer coisa que você possa imaginar. Há tantas questões envolvidas ... Eu me sentia traído, quero dizer, eles possuíam uma parte de mim que não poderia jamais ser recuperada."

Em 1984 John Moore processou o seu médico, a diretoria da Universidade da Califórnia em Los Angeles e as companhias farmacêuticas que licenciaram as células "MO". Em 1990 o Supremo Tribunal da Califórnia decidiu que o médico de John Moore tinha violado seu dever fiduciário para com o paciente ao não revelar interesses financeiros e de pesquisa pelas células de John. Entretanto, o Tribunal também negou o pedido de John Moore de ser proprietário da célula removida de seu corpo arguindo que a pesquisa em células humanas desempenha um papel crítico na pesquisa médica. E assim também é a história da tentativa americana de patentear as células de uma índia Guaymi. Serão esses assuntos de direitos humanos? Seja qual for sua resposta, tais casos pedem a inclusão de abusos corporativos de direitos humanos na equação maior, no quadro de referência mais amplo. Como é que nós podemos falar sobre genocídio na África sem falar sobre a indústria armamentista? Na verdade como é que nós podemos falar sobre o Iraque sem considerar o papel do complexo industrial militar? A comercialização da vida ajuda a trivializar a vida. A necessidade de testar armamentos, também. Nós precisamos levar o sofrimento a sério. Será uma questão de direitos humanos o recente contrato de Sierra Blanca assinado pelo Governador de Texas, George Bush, para a instalação de um depósito de lixo nuclear numa comunidade méxico-americana de baixa renda? O depósito fica a 16 milhas do Rio Grande e acima de uma fonte d'água (Nation, 09/03/1998, p. 19). Um de meus colegas em Berkeley diz que não porque o motivo principal não é destruir vidas méxico-americanas, isso seria apenas um subproduto do negócio.

\section{Observacõos finais}

Uma noção mais inclusiva de direitos humanos serve para reduzir a hipocrisia ao incluir, entre as preocupações, "nossas" práticas tanto quanto as "deles" e ao nos aproximar das causas básicas. Os americanos talvez não considerem o Presidente Carter como um dos nossos mais ilustres presidentes mas pessoas de outros países o fazem porque ao menos ele deu importância simbólica aos direitos humanos na política externa. Aquilo foi apenas o 
começo porque tal capital simbólico funciona apenas se nós agimos de forma equitativa. Resumindo, a credibilidade de um espírito de direitos humanos requer que nós olhemos para nós mesmos tanto quanto para aqueles que desejamos ajudar. Essa credibilidade também requer uma atenção maior para as causas básicas - o que nos obriga, entre outras coisas, a olhar para as vendas da indústria americana em casa e no exterior. A globalização não precisa ter conotações predominantemente negativas; sabemos disso pela investigação histórica de antigos esforços pré-europeus de globalização (Abu-Lughod, 1989). Mas um grande salto adiante nas conquistas de direitos humanos vai exigir que o trabalho corpo a corpo, de grupo a indivíduo ou de grupo a grupo mundo afora seja baseado num conhecimento da distribuição do poder e das ações resultantes das iniquidades do poder tanto em casa quanto no exterior.

(Traduzido do inglês por Pedro Fonseca)

\section{Referências}

ABU-LUGHOD, J. Before European hegemony: the world systems A.D. 1250-1350. New York: Oxford University Press, 1989.

BERGER, J. A New Deal for the world: Eleanor Roosevelt and American foreign policy. New York: Columbia University Press, 1981.

BURROWS, B. Second thoughts about U.S. Patent \#4,438,032. Genewatch, v. 10, n. 2-3, October 1996.

COCO, L. Silicone breast implants in America: a choice of the "official breast'?. In: NADER, L. (Ed.). Essays on controlling processes. Berkeley: Kroeber Anthropological Society, 1994. (Kroeber Anthropological Society Papers n. 77).

DENNISTON, G.; MILOS, M. F. (Ed.). Sexual mutilations - a human tragedy. New York: Plenum Press, 1997.

FAIZ, A. Health care under the Taliban. Lancet, n. 349, p. 1247-1248, April 1997. 
FALK, R. Cultural foundations for the international protection of human rights. In: AN-NA'IM, A. A. (Ed.). Human rights in cross-cultural perspectives: a quest for consensus. Philadelphia: University of Pennsylvania Press, 1992. p. 44-64.

FEIBLEMAN, P. Natural causes. Double Take Magazine, Winter Issue, 1997.

HEGGENHAUGEN, H. K. More than just interesting: anthropology, health and human rights. Boston: Dept. of Social Medicine, Harvard Medical School, 1997.

HERNANDEZ-TRUYOL, B. E. Women's rights as human rights - rules, realities and the role of culture: a formula for reform. Brook Journal of International Law, v. 21, n. 3, p. 605-677, 1996.

HOFF-WILSON, J.; LIGHTMAN, M. (Ed.). Without precedent: the life and career of Eleanor Roosevelt. Bloomington: Indiana University Press, 1984.

HOSKINS, E. Public health and the Persian Gulf War. In: LEVY, B. S.; SIDEL, V. W. (Ed.). War and public health. New York: Oxford University Press, 1997. p. 254-277.

KUENYEHIA, A. The Impact of structural adjustment programs on women's international human rights: the example of Ghana. In: COOK, R. (Ed.). Human rights of women: national and international perspectives. Philadelphia: University of Pennsylvania Press, 1994. p. 422-436.

LASH, J. P. Eleanor. the years alone. New York: W. W. Norton \& Co, 1972.

MANN, J. M. Health and human rights. BMJ, n. 312, p. 924-925, 1996.

MORSEY, S. A. Bodies of choice: norplant experiments trials on Egyptian women. In: MINTZES, B.; HARDON, A.; HANHART, J. (Ed.). Norplant under her skin. Delft: Eburon, 1993.

NADER, L. Controlling processes - tracing the dynamic components of power. Current Anthropology, v. 38, n. 5, Dec. 1997. 
NADER, L.; OU, J. C. Idealization and power; legality and tradition in Native American law. Oklahoma City University Law Review, v. 23, n. 1, Spring 1998.

NASHASHIBI, S.; NADER, L.; ADNAN, E. Arab women artists. In: NASHASHIBI, S.; NADER, L.; ADNAN, E. Forces of change: artists of the Arab World. Washington, D.C.: The National Museum of Women in the Arts, 1994. p. 1-36.

RENTELN, A. International human rights: universalism versus relativism. Newbury Park: Sage Publications, 1990.

RODRIGUEZ-TRIAS, H. Women's health, women's lives, women's rights. American Journal of Public Health, v. 82, n. 5, May 1992.

ROMANY, C. State responsability goes private. In: COOK, R. (Ed.). Human rights of women: national and international perspectives. Philadelphia: University of Pennsylvania Press, 1994.

SAID, E. W. Occidentalism. New York: Random House, 1979.

SCHEPER-HUGHES, N. Virgin territory: the male discovery of the clitoris. Medical Anthropology Quarterly, v. 5, n. 1, p. 25-28, March 1991.

SHEEHAN, E. A. Victorian clitoridectomy. Isaac Baker Brown and his harmless operative procedure. In: LANCASTER, R.; DI LEONARDO, M. (Ed.). The gender/sexuality reader: culture, history, political economy. New York: Routledge, 1997. 